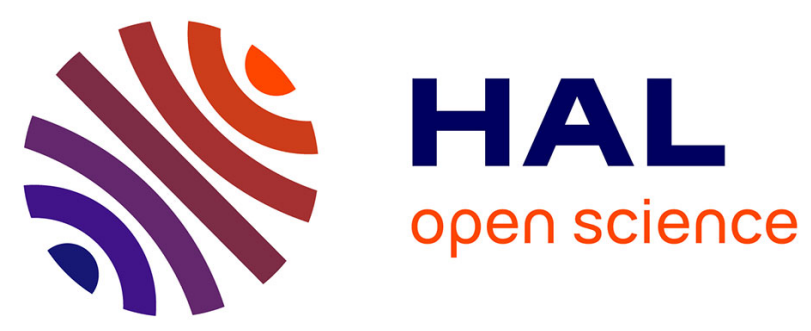

\title{
Loss Model Impact on Multi-Physical Coupling Designed for Sizing Optimization of Electrical Machines
}

\author{
Wissem Bekir, Oualid Messal, Louis Lambourg, Frédéric Dubas, Souad
} Harmand, Afef Kedous-Lebouc, Frédéric Gillon

\section{- To cite this version:}

Wissem Bekir, Oualid Messal, Louis Lambourg, Frédéric Dubas, Souad Harmand, et al.. Loss Model Impact on Multi-Physical Coupling Designed for Sizing Optimization of Electrical Machines. International Conference on Ecological Vehicles and Renewable Energies, Sep 2020, Monte-Carlo, Monaco. 10.1109/EVER48776.2020.9242987 . hal-03053043

\section{HAL Id: hal-03053043 \\ https://hal.science/hal-03053043}

Submitted on 10 Dec 2020

HAL is a multi-disciplinary open access archive for the deposit and dissemination of scientific research documents, whether they are published or not. The documents may come from teaching and research institutions in France or abroad, or from public or private research centers.
L'archive ouverte pluridisciplinaire HAL, est destinée au dépôt et à la diffusion de documents scientifiques de niveau recherche, publiés ou non, émanant des établissements d'enseignement et de recherche français ou étrangers, des laboratoires publics ou privés. 


\title{
Loss Model Impact on Multi-Physical Coupling Designed for Sizing Optimization of Electrical Machines
}

\author{
W. Bekir ${ }^{1}$, O. Messal ${ }^{1}$, L. Lambourg 2 , F. Dubas 3 , S. Harmand ${ }^{2}$, A. Kedous-Lebouc ${ }^{4}$, and F. Gillon \\ ${ }^{1}$ Univ. Lille, Centrale Lille, Arts et Metiers ParisTech, HEI, EA 2697, L2EP, F-59000 Lille, France. \\ ${ }^{2}$ University of Valenciennes, LAMIH, CNRS UMR 8201, Campus le Mont Houy, Valenciennes F59313. \\ ${ }^{3}$ Département ENERGIE, FEMTO-ST, CNRS, Univ. Bourgogne Franche-Comté, F90000 Belfort, France. \\ ${ }^{4}$ Univ. Grenoble Alpes, CNRS, Grenoble INP, G2Elab, F38000 Grenoble, France. \\ wissem.bekir@centralelille.fr, frederic.gillon@centralelille.fr
}

\begin{abstract}
This article analyzes and highlights the impact of an iron loss model on temperature estimation within a multiphysical model of a radial-flux permanent-magnet (PM) synchronous machine (PMSM) for traction application. Three iron loss models have been compared in terms of computing time and accuracy within the machine torque-speed plane. This study underlines the iron loss calculation impact on the temperature estimation in the PMSM in relation with the required performances.
\end{abstract}

Keywords - Electrical machines, electric traction vehicle, iron losses, multi-physical model.

\section{INTRODUCTION}

The energetic efficiency improvement in the transport sector and particularly in the automotive field has become a major challenge of crucial importance. How to reduce the energy consumption? One possible way is by enhancing the performances of traction systems. In order to improve or optimize these systems, we should be able to correctly model them considering all the main phenomena involved including losses. Thus, a multi-physical model is required. This model should be sufficiently accuracy but at the same time, its computing time should be short due to the high number of model evaluations [1].

One of the difficulties faced during electrical traction chain design is to be able to estimate enough accurately the iron loss [2]. In practice, the electric traction machines operate in a wide range of torque and speed (Torque/Speed plane), leading to variable working frequency. In addition, these machines have weakening mode control. For a relevant iron loss prediction, it is mandatory that the model takes into consideration all these behaviors.

During the last years, the machine iron loss evaluation has become a challenge of many researches. Even though the iron loss relation to the total loss varies according to the machine under consideration, thy can be dominant when the frequency is high [3]. Indeed, at high-speed, the iron loss can reach $80 \%$ of the total losses [4]. This is prejudicial, because, the loss downgrades the energy efficiency of the machine on the one hand, and causes the overheating of its magnetic parts on the other hand. In this way, the machine temperature rise depends partially on the iron loss estimation. Studying this relation requires a multi-physical model [5]. The use of such model coupled to a thermal one is not common. The developed model will allow estimating not just the traction machine yield but also the temperature inside the machine, which means that it will be possible to analyze the impact of iron loss estimation error as a temperature variation.

Three iron loss models with different complexity levels have been investigated. The Loss Surface (LS) hysteresis model will be taken as a reference [4]. This model is considered to be the most accurate but is time-consuming. An intermediate model fast enough and with few coefficients is later on selected [6]. Finally, the classical Steinmetz model [7] is used for its simplicity and high speed.

The paper is organized as follows: the section II introduces the multi-physical coupling as well as the iron loss models and their calculation times. The section III describes first the coupling developed for to the PMSM, then the iron loss results are presented and discussed from a local and global point of view is studied. The section IV shows the iron loss calculation impact on the machine performances for eight operating points, and then the loss and efficiency cartographies are presented. Finally, a comparison between iron loss models is made by considering the root-mean-square deviation (RMSD) between the loss models in terms of power (W) and temperature $\left({ }^{\circ} \mathrm{C}\right)$.

\section{MultiPhySICAL MODEl FOR SizING OPTIMIZATION}

Traction machine designing requires a multi-physical model. The magnetic and thermal model are based on lumped constant managing a compromise that includes computing time and accuracy. Fig. 1 represents the multi-physical model structure with three related layers.

The first layer integrates a cost model and a generalized nonlinear adaptive magnetic equivalent circuit (MEC). This model is mesh-based reluctance network. It takes into consideration the saturation effect and uses the "air-gap sliding-line technic" [8] in order to incorporate the machine motion. The method allows a different discretization between the stator and the rotor, so a possible adaptation of the mesh density. The second layer contains three iron loss models with different level of accuracy and calculation times. The third layer includes an aero-thermal model (SAME) allowing fast and accurate determination of the thermal machine behavior by taking into account the convective exchanges, thermal conduction and the power loss distribution. This model uses the nodal method, which consists in discretizing the geometry into many isothermal volumes wherein the centers are linked by thermal conductances [9]. Knowing the local iron and Joule losses within these volumes, the model provides temperature cartography of the machine. 


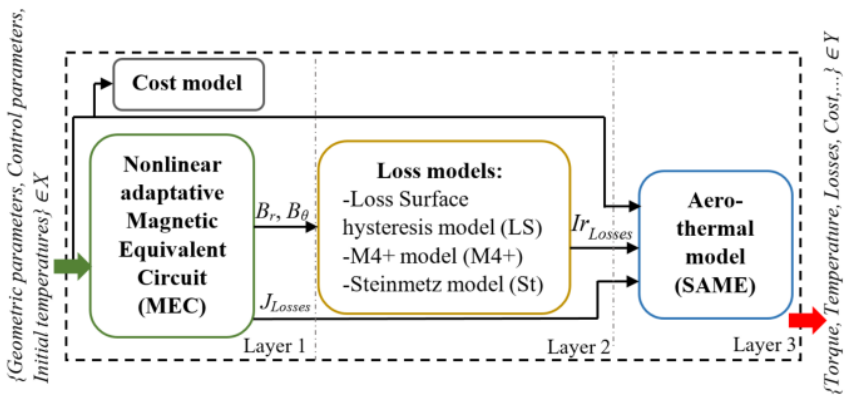

Fig. 1. Multi-physical model for sizing by optimization.

This coupling is built as a single function. The inputs are: the geometrical machine parameters (10), the 3 control parameters (stator current $I_{\text {smax }}(\mathrm{A})$, the phase angle between the stator current and voltage $\psi\left({ }^{\circ}\right)$ and frequency $f(\mathrm{~Hz})$ ), as well as the initial PMs and coil temperatures. The outputs are: the machine electromagnetic performances (torque, etc.), the Joule loss, the iron loss according to the used model (LS, $\mathrm{M} 4+, \mathrm{St}$ ) and the temperatures obtained from the whole calculated losses. The function includes also some options that allow the model configuration (models choice, parallelization, display, etc.). The generated quantities are spatio-temporal. For example, the radial and tangential components of magnetic flux density (viz., $B_{r}$ and $B_{\theta}$ ) are calculated in each cell of the MEC as a function of the rotor position (i.e., time dependence). The model structuring as well as its data are of prime importance to rigorously study the machine behaviors.

\section{A. Zoom on the iron loss models}

Many models are used in literature to estimate the iron losses in magnetic circuits. Three models have been selected herein. The first model is based on a global iron loss calculation according to the classic Steinmetz $(\mathrm{St})$ equation [7]:

$$
I r_{\text {Losses }}=k_{\text {se }} f^{\alpha} B_{\max }^{\beta}
$$

Eq. (1) is an empirical formulation requiring three coefficients to quickly and roughly estimate the iron loss. The second model called M4+ uses loss decomposition into three terms. The first term represents hysteresis losses (major loops of $\Delta B_{p p}$ pic to pic flux density variation), the second one represents eddy currents and the third one is introduced to consider minor hysteresis loops with $\delta B_{l}$ of $B$ variation [6]. As the previous model, the M4+ model includes three adjustable coefficients $\left(k_{h 1}, k_{h 2}, \alpha_{p}\right)$ to characterize the magnetic loss under variable flux density waveform.

$$
\begin{aligned}
I_{\text {Losses }} & =\left(k_{h 1} \Delta B_{p p}+k_{h 2} \Delta B_{p p}^{2}\right) f+\alpha_{p} \frac{1}{T} \int_{0}^{T}\left(\frac{d B}{d t}\right)^{2} d t \\
& +\sum_{i=1}^{n}\left(k_{h 1} \delta B_{i}+k_{h 2} \delta B_{i}^{2}\right) f
\end{aligned}
$$

The third model is the so-called LS (Loss Surface) model [10], it is considered herein as the reference model. It is a dynamic $H(B)$ model relating the applied excitation field $H$ to the average magnetic flux density $B$ in the cross section of the material sheet. This model precisely evaluates the iron loss but requires some specific measurements (under a controlled triangular waveform $B(t)$ and variable frequency) introduced in the form of a dynamic surface depending on $B$ and $d B / d t$. In order to describe the macroscopic behavior of the material, a static hysteretic model [11] is introduced in the main formulation (3).

$$
H(B, d B / d t)=H_{\text {stat }}(B, \text { history })+H_{d y n}(B, d B / d t)
$$

To predict the $2 \mathrm{D}$ vector excitation behavior observed in some parts of the machine magnetic circuit, the LS and M4+ models use the magnetic flux density decomposition according to two axes $B_{\theta}$ and $B_{r}$ that are projected on a new orthonormal coordinate [10]. The Steinmetz model, calculates the loss based only on the flux density module.

The M4+ and Steinmetz model coefficients were identified referring to the LS model under sinusoidal waveform for different frequencies and flux density amplitudes. Fig. 2 shows the iron loss $\operatorname{Ir}_{\text {Losses }}\left(B_{\max }\right)$ curves for different frequencies. The relative error is mainly low for important flux density but might become more important for low flux density values.

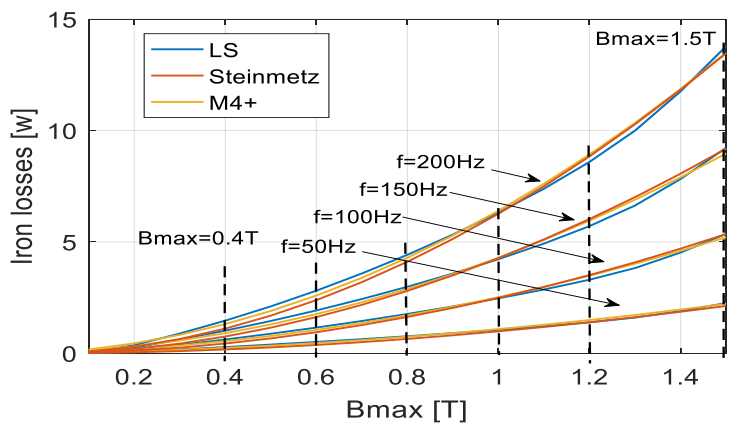

Fig. 2. Ir Losses $\left(B_{\max }\right)$ curves for different frequencies under sinusoidal waveforms.

\section{B. Principle of the iron loss machine computation}

The MEC discretization principle is shown in Fig. 3. The computational domain is discretized according to the tangential and radial directions [8, 10]. Each Block of the MEC contains four branches and thus gives four cells, having two flux density components. The iron loss is computed in each spatial discretization cell. The principle is well detailed in [10].

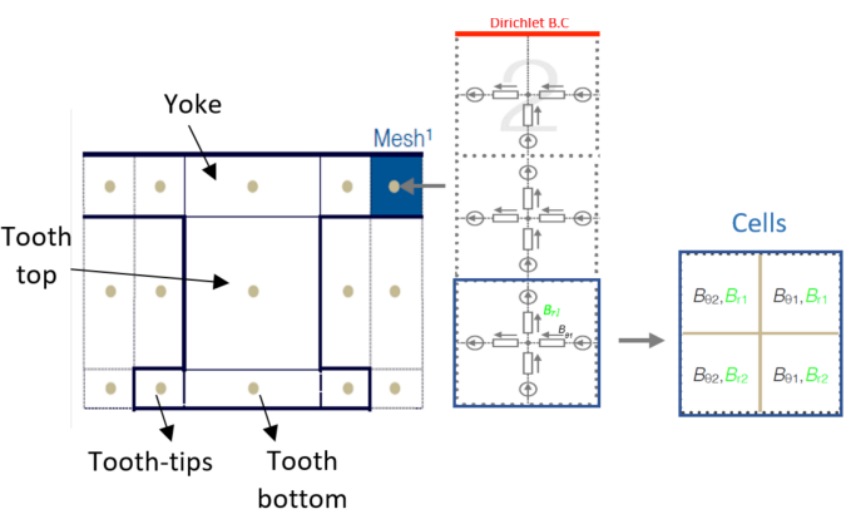

Fig. 3. Spatial discretization principle.

\section{Computing time}

The main advantage of the developed multi-physical model is the reduced calculation time for both magnetic and thermal models. Table I shows time calculation for the different models. 
The nonlinear adaptive MEC is relatively fast with the used spatio-temporal discretization level. The thermal model SAME without thermal transition has its own spatial discretization. The model is so fast. Calculation times of iron losses models depend on the spatial discretization of MEC. In this case, and with the used LS model version, loss calculation time is much higher that of the MEC, while it is insignificant for the Steinmetz model.

TABLE I. Calculation times.

\begin{tabular}{|c|c|c|c|c|}
\hline \multicolumn{5}{|c|}{ Computing time [s] } \\
\hline MEC & LS & M4+ & Steinmetz & SAME \\
\hline 3.8 & 56 & 0.1 & 0.003 & 0.8 \\
\hline
\end{tabular}

\section{Application to a Traction Motor}

The study has been done on a radial-flux PMSM with 24slots/16-poles. The stator has 3 phases with double-layer concentrated winding distribution supplied by sinusoidal current waveform with a maximum amplitude $I_{\text {smax }}$. The simplified topology of the machine is shown in Fig. 7. The Iron losses within the machine stator are studied from both local and global points of view. The rotor losses are neglected.

\section{A. Local point of view}

A study has been conducted on iron loss calculation in the mesh cells with LS, M4+ and Steinmetz models. Fig. 4.a and Fig.4.b show respectively the results obtained one stator teeth within the cells with Steinmetz and M4+ models for the

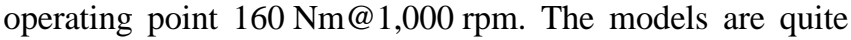
similar with few differences in amplitudes.

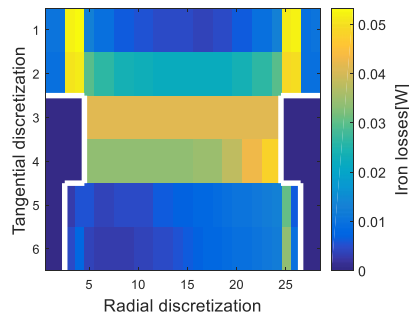

Fig. 4. a. Steinmetz,

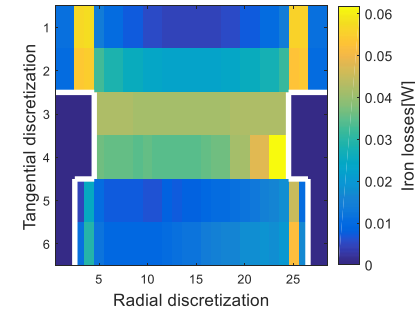

Fig. 4. b. M4+
Fig. 4. Iron loss distribution in a stator tooth.

Fig. 5 shows the iron loss calculation inside the stator yoke and for the same operating point using the three models for the 56 cells in this part of the teeth. The models M4+ and Steinmetz lightly underestimate the loss calculation in comparison to the LS model. The calculation error remains low.

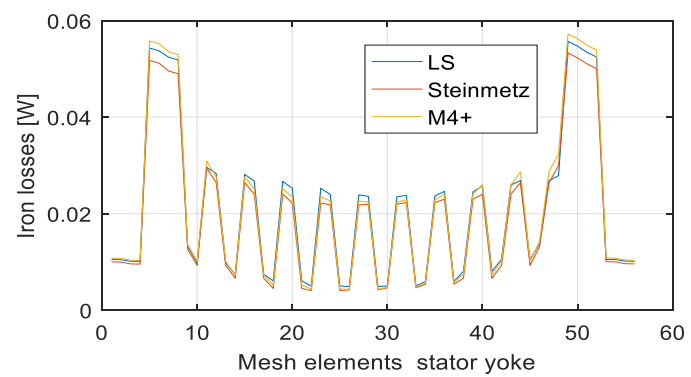

Fig. 5. Iron loss calculation in the 56 cells of the stator yoke part of the tooth shown in Fig.4.

However, the behavior is different for other cases. For example, Fig. 6 illustrates the loss calculation using the three models in the case of the $75 \mathrm{Nm@6,000} \mathrm{rpm} \mathrm{operating} \mathrm{point}$ (high speed, low torque) and in the 8 cells of tooth-tips. The result shows that the M4+ model overestimates the loss and while the Steinmetz model underestimates it in this same case. For this operating point, the error becomes significant.

It is possible to study the reasons behind these calculation differences by focusing on the flux densities time variations in the cells as illustrated in Fig. 6 (right side), and by analyzing more closely the calculation principle of each model. However, this analysis should be achieved at a local, the aim being to examine not the errors sources but their effects on the coupling and the final temperature distribution in the machine.

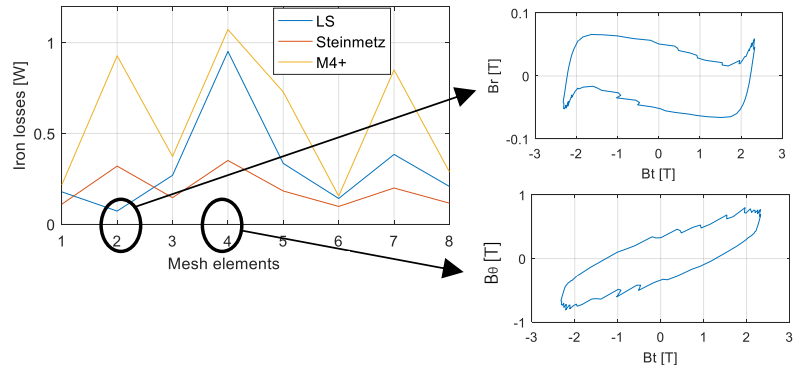

Fig. 6. Loss calculation in a stator tooth-tip cells.

\section{B. Global point of view}

Table II gives the local loss computed, at 160 Nm@1,000 rpm operating condition, in each part of the stator for one pole as well the global one reported for the whole machine ( 8 poles). The total loss difference obtained is $16 \mathrm{~W}$ and $6 \mathrm{~W}$ between the Steinmetz and the LS model and between LS and M4+ models respectively.

Table II. Iron losses calculation at 160 Nm@1,000 rpm.

\begin{tabular}{|l|c|c|c|c|c|}
\hline \multirow{2}{*}{} & \multicolumn{5}{|c|}{ Iron losses [W] } \\
\cline { 2 - 6 } & Yoke & Tooth top & $\begin{array}{c}\text { Tooth } \\
\text { bottom }\end{array}$ & Tooth-tips & Overall \\
\hline Steinmetz & 3.3 & 4.67 & 0.82 & 0.3 & 72 \\
\hline M4+ & 3.5 & 4.8 & 1.39 & 0.57 & 82 \\
\hline LS & 3.5 & 4.9 & 1.51 & 1.1 & 88 \\
\hline
\end{tabular}

Fig. 7 shows the mass specific iron loss distribution within different parts of the stator. This result is obtained using the LS model for $160 \mathrm{Nm@1,000} \mathrm{rpm.} \mathrm{Iron} \mathrm{loss} \mathrm{is} \mathrm{focused} \mathrm{in} \mathrm{the}$ low part of the tooth-tips.

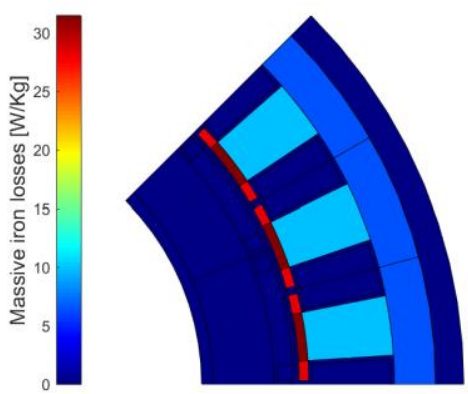

Fig. 7. Specific iron losses in (W/kg) distribution at 160Nm@1000rpm.

\section{IMPACT OF IRON LOSS MODELS ON THE MOTOR PERFORMENCES}

We should not conclude on the accuracy of the loss models based on a single operating point. For electric/hybrid/fuel cell 
vehicle application, extended the whole torque-speed variation should be investigated. It is necessary to evaluate the iron loss proportion against the Joule loss to bring to light how relevant it is to consider these iron losses for a correct evaluation of the machines thermal behaviour.

\section{A. Results on chosen operating points}

In order to study the machine within the torque-speed plane, it is necessary to calculate the machine control parameters for each operating point. Considering the case of a maximum torque per ampere (MTPA) classical control, the optimal control consists in identifying the maximum current amplitude $I_{\text {smax }}$ and the control angle $\psi$ minimizing the current

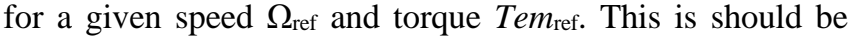
performed under a voltage constrant $V_{\text {eff }}$ and bounded ranges for both $I_{s \max }$ and $\psi$. It is therefore a mono-objectif non-linear constrained optimization problem, that could be written as in (4). A gradient method is an effective solution for this kind of problems, which are relatively smooth. In this example, the current minimization $I_{\text {smax }}$ is equivalent to the Joule loss minimization.

$$
\begin{aligned}
& \min _{\left(\psi, I_{\text {max }}\right)}\left(I_{s \max }\right) \approx \min _{\left(\psi, I_{\text {max }}\right)}\left(J_{\text {Losses }}\right) \\
& \psi_{\min } \leq \psi \leq \psi_{\max } \\
& I_{\min } \leq I_{s \max } \leq I_{\text {Max }} \\
& V_{\text {eff }}-V_{\text {effmax }} \leq 0 \\
& T_{\text {em } m_{\text {ref }}}-T_{\text {em }} \leq 0 \text { with: } \Omega=\Omega_{\text {ref }}
\end{aligned}
$$

Fig. 8 shows the ratio in $\%$ of the iron losses to the Joule losses for eight operating points of the studied motor numbered from 1 to 8 and distributed on the torque-speed plane. These results are obtained using MTPA control. The iron losses are calculated using the LS model. The iron losses can be neglected in the case of point no.1 i.e., at low speed and high torque. However, it becomes important for the other points, especially at low speed and low torque, and in the weakening regime at high speed.

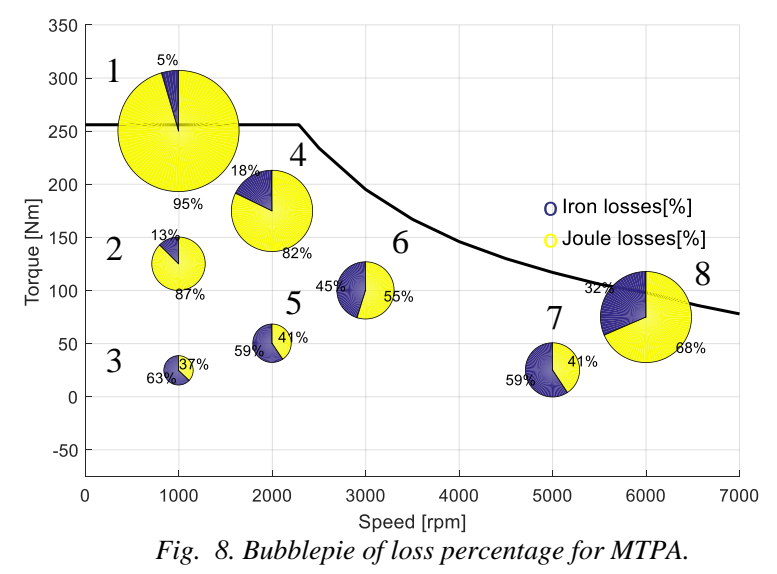

The advantage of the developed multi-physical model is its ability to evaluate the temperature distribution in the machine for the steady state. Indeed, the model inputs are the initial temperatures of the active winding part $T_{0}(1)$, the winding heads $T_{0}(2)$ and the magnets $T_{0}(3)$. They are used in the resolution of the MEC magnetic model. So to evaluate the steady state final temperatures, an iterative procedure or an optimization process should be added. An iterative loop has been introduced in the MTPA problem, minimizing the difference between the initial $\left(\boldsymbol{T}_{\boldsymbol{0}}\right)$ and final temperatures $\left(\boldsymbol{T}_{\boldsymbol{f}}\right)$ in the thermal model. An overview of the optimization problem MTPA_T is shown in (5):

$$
\begin{aligned}
& \min _{\left(\psi, I_{\text {max }}\right)}\left(I_{s \max }\right) \approx \min _{\left(\psi, I_{\text {max }}\right)}\left(J_{\text {Losses }}\left(T_{0}\right)\right) \\
& \min _{\left(T_{0}(1), T_{0}(2), T_{0}(3)\right)}\left\|T_{f}-T_{0}\right\| \\
& \psi_{\min } \leq \psi \leq \psi_{\max } \\
& I_{\min } \leq I_{s \max } \leq I_{\text {Max }} \\
& V_{\text {eff }}-V_{\text {effmax }} \leq 0 \\
& T_{\text {em ref }}-T_{\text {em }} \leq 0 \text { with }: \Omega=\Omega_{\text {ref }}
\end{aligned}
$$

(5) explicitly shows the two nested loops. Nesting these loops increases the running time.

Fig. 9 illustrates iron and Joule losses rates, under MTPA_T control and for the same eight operating points studied before. The point no. 1 becomes unattainable. Iron and Joule loss proportions have also changed. For instance, for the point no. 8 the iron loss percentage is decreased from $32 \%$ to $16 \%$.

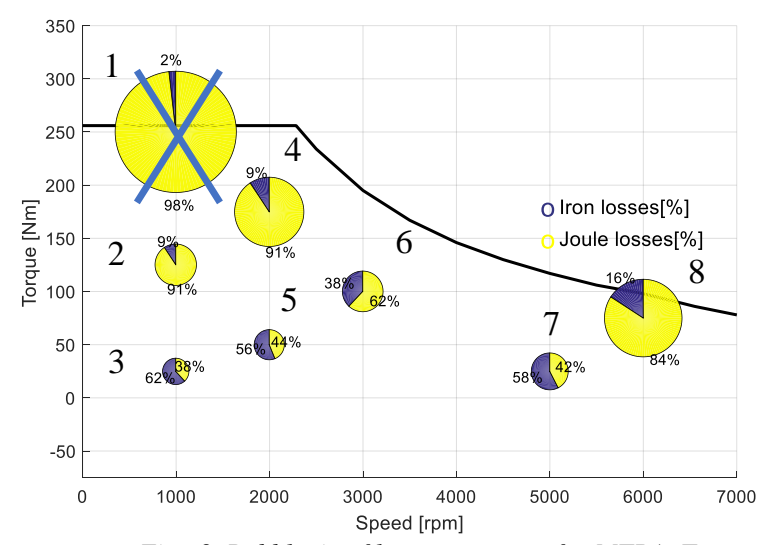

Fig. 9. Bubblepie of loss percentage for MTPA_T.

The evolution of the temperature conditions change, thus the values and the distribution of global losses. Fig. 10 and Fig. 11 show respectively iron and Joule losses for the eigth operating points and the two control cases. Therefore, the control does not impact the iron loss calculation but rather the Joule losses, especially for the points no. 4 and 8 . The point no. 1 has the highest torque and current, which leads to an important increase of the temperature and thus a reduction of the PMs flux. Given the imposed current limit, the desired torque could not be reached.

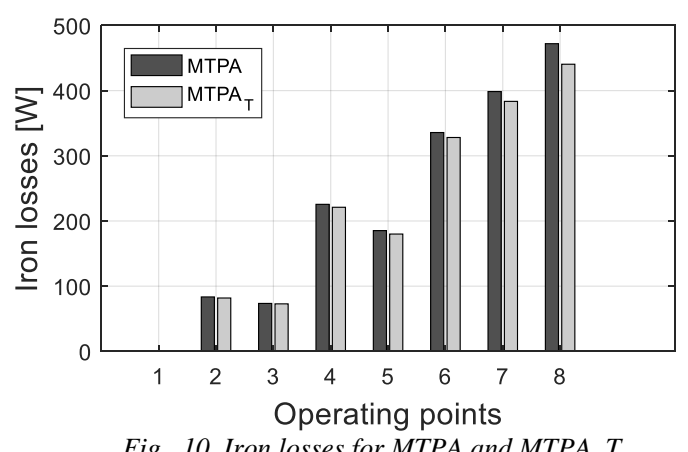

Fig. 10. Iron losses for MTPA and MTPA_T. 


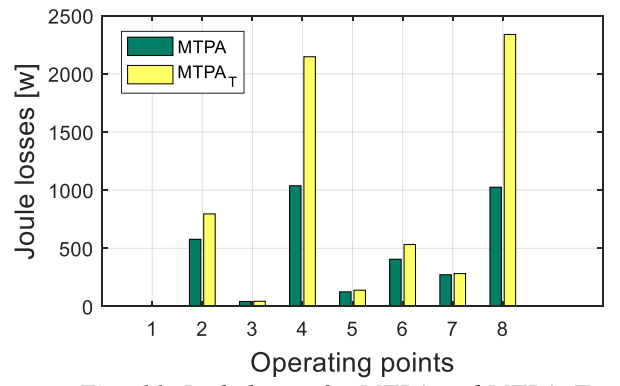

Fig. 11. Joule losses for MTPA and MTPA_T.

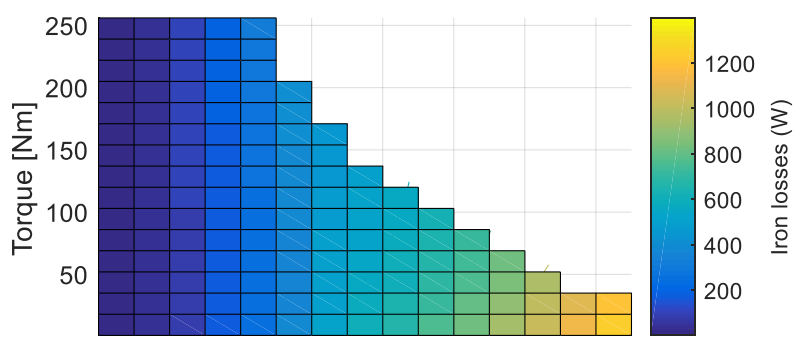

1000200030004000500060007000 Speed [rpm]

Fig. 12. Iron losses cartography.

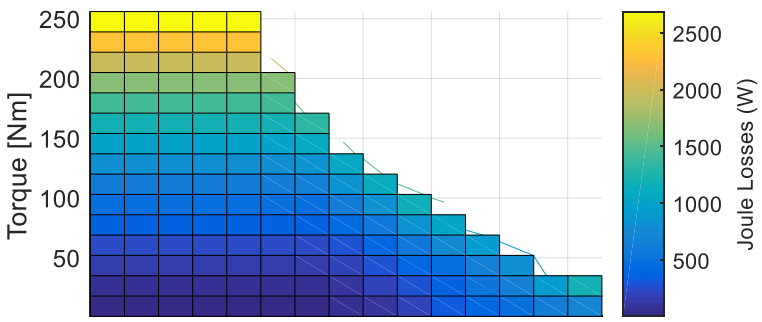

1000200030004000500060007000 Speed [rpm]

Fig. 13. Joule losses cartography.

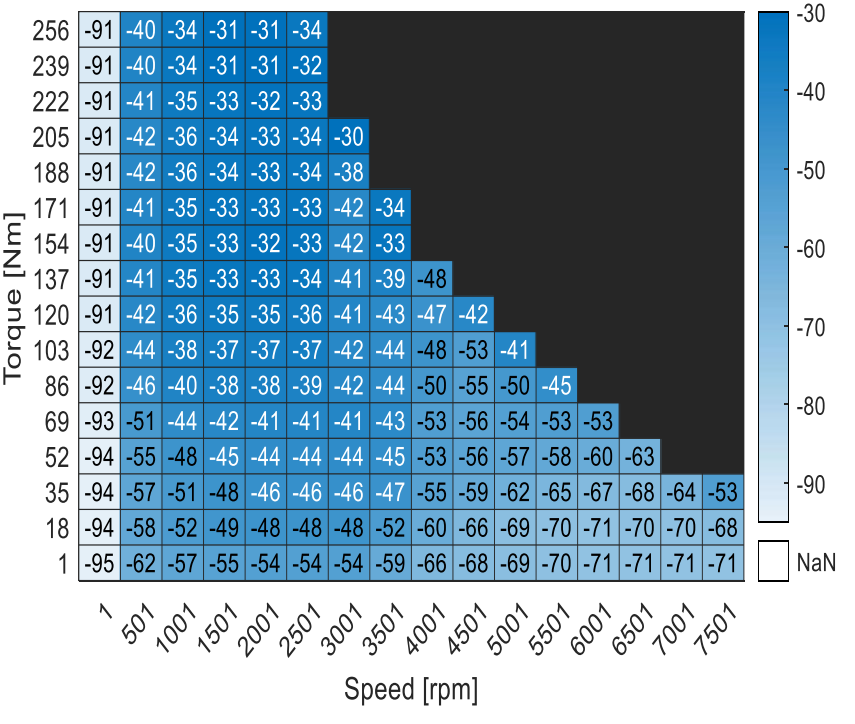

Fig. 15. a. NRMSD[\%]: Steinmetz Vs LS.

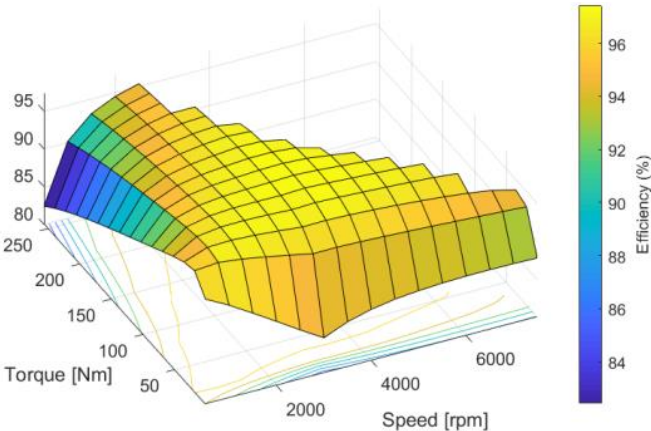

Fig. 14. Efficiency cartography.

\section{B. Results in term of temperature}

Starting from the MTPA control previously defined, loss models have been compared in terms of loss and temperature prediction an observed difference in temperature being directly linked to an error on the loss. An important error might not lead to an important increase of the temperature. Conversely, a low error might increase the temperature beyond the tolerated limit.

Fig. 15.a shows the relative error on iron losses made by using the Steinmetz model in comparison with the LS model. Fig.15.b illustrates the absolute error, which means the difference (in Watt) between the two model losses. Errors are important for this model with the realized identification. To effectively give a ruling about the models in a global point of view, the normalized root mean square derivation (NRMSD) and the root mean square derivation (RMSD) have been calculated respectively for the relative and the absolute errors. The obtained values are respectively $58 \%$ and $248 \mathrm{~W}$. In this example, Steinmetz model underestimates the iron loss. A purely mathematic global correction of the Steinmetz model has been tested by multiplying the iron loss by a correction factor of 2.02 obtained by optimization procedure. The obtained NRMSD is then reduced from 58 to $28 \%$.

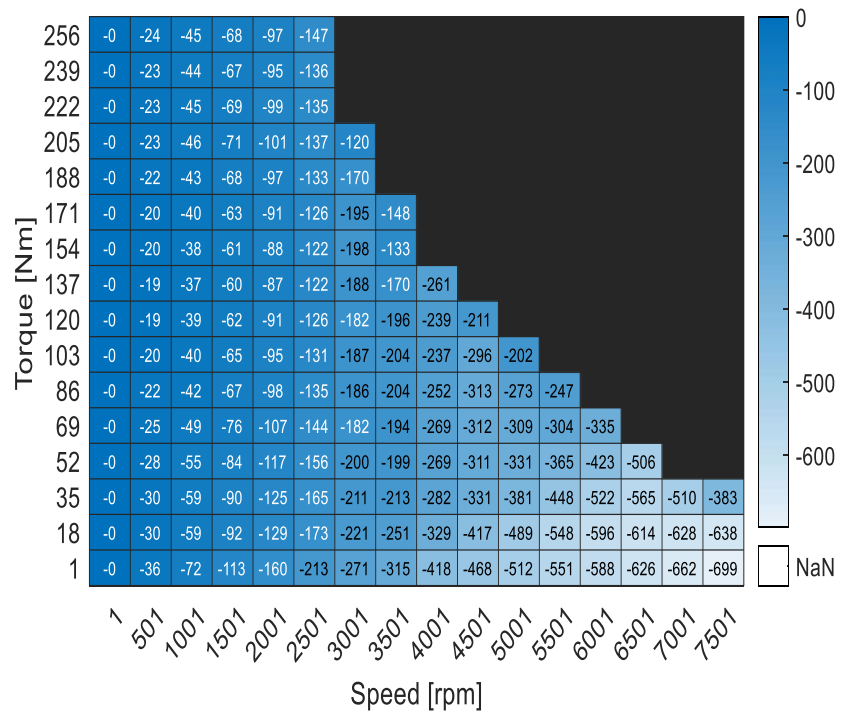

Fig. 15. b. RMSD[W] : Steinmetz Vs LS.

Fig. 15. Error of the Steinmetz model in comparison with LS model for iron losses. 


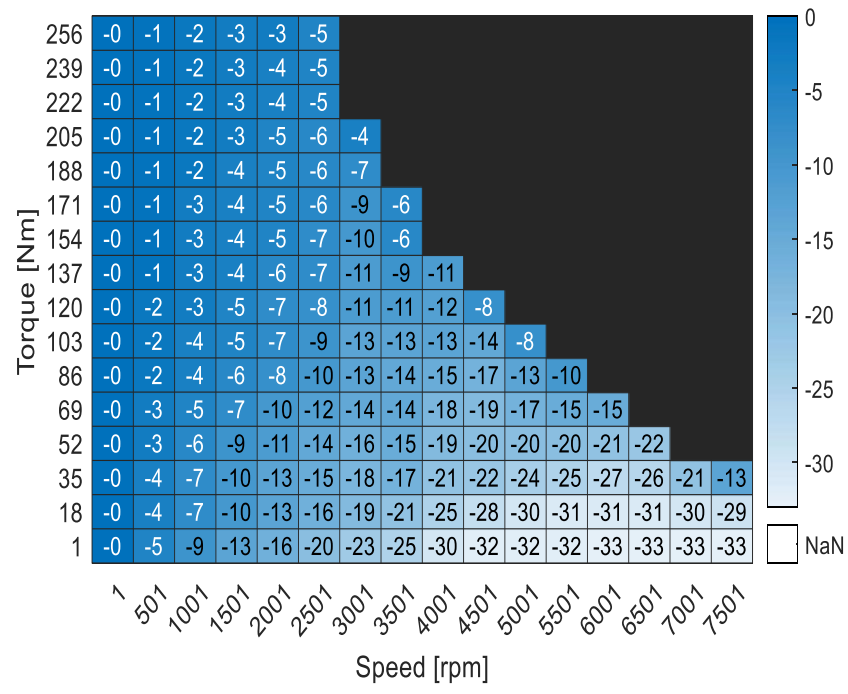

Fig. 16. a. NRMSD[\%]: Steinmetz Vs LS.

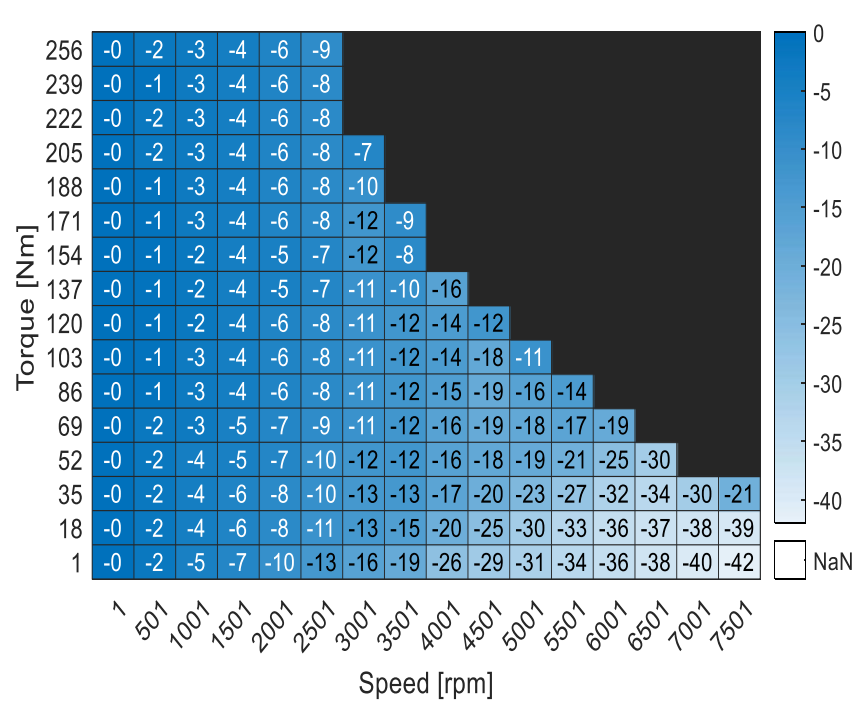

Fig. 16. b. RMSD[W] : Steinmetz Vs LS.

Fig. 16. Impact of the relative error on temperature computing between Steinmetz and LS models.

However, the iron loss becomes overestimated in some regions of the torque-speed plane and still remain underestimated in others. Fig.16.a shows the impact of the relative error on the computed temperatures when both Steinmetz and LS models are used. The loss model influence is analyzed through the temperature error. The NRMSD of Fig.16.a is 3\% and the RMSD of Fig.16.b is $15^{\circ} \mathrm{C}$. However, temperature discrepancies are significant and reach $-42^{\circ} \mathrm{C}$ at high speed while they remain acceptable in the constant torque area. These discrepancies significantly increase in the weakening mode zone where iron loss prevails. Notice that the same comparison has been achieved with the M4+ model. The results show that the M4+ is more accurate than the Steinmetz one and provides an RMSD of $117 \mathrm{~W}$ for loss leading to $7^{\circ} \mathrm{C}$ deviation in temperature.

\section{CONCLUSION}

This article presents the impact of the iron loss model on a multi-physical coupling developed for sizing by optimization of electrical machines. Section II describes the multi-physical approach and three iron loss models. Section III presents a comparison from a local and global point of view in the case of a radial-flux PMSM. These results provide an idea on the iron loss distribution within the machine and show that it is not sufficient to compare models for just one operating point. Section IV develops the iron loss calculation impact on the machine performance evaluation. Firstly, a study was conducted at serval operating point about the control and the temperature impact on the computation of the iron loss as well as their relative importance in relation to Joule losses. Then a comparative study has been carried out in the whole torquespeed plane regarding the predicted iron losses and their influence on the evaluated thermal behavior of the machine.

\section{ACKNOWLEDGMENT}

This work was supported by RENAULT-SAS, Guyancourt, France, through the program COCTEL (Conception Optimale des Chaines de Traction ELectrique) financed by the French Agency for Environment and Energy Management (ADEME).

\section{REFERENCES}

[1] P. Caillard, F. Gillon, S. Randi, and N. Janiaud, "Mono and bi-Level optimization architectures for powertrain design," COMPEL - The international journal for computation and mathematics in electrical and electronic engineering, vol. 35, no. 3, March 2016.

[2] A. Frias, A. Kedous-Lebouc, C. Chillet, L. Albert, L. Calegari, and O. Messal, "Loss Minimization of an Electrical Vehicle Machine Considering Its Control and Iron Losses," IEEE Trans. Magn., vol. 52, no. 5, May 2016, Art ID 8102904.

[3] S. Xue, Z.Q. Zhu, Y. Wang, J. Feng, S. Guo, Y. Li, Z. Chen, and J. Peng, "Thermal-Loss Coupling Analysis of an Electrical Machine Using the Improved Temperature-Dependent Iron Loss Model," IEEE Trans. Magn., vol. 54, no. 11, Nov. 2018, Art ID 8105005.

[4] M. Dinh Bui, and U. Schaefer, "Core losses measurement technique for high frequency and flux density of switched reluctance machines," XXth International Conference on Electrical Machines (ICEM), Marseille, 2012, pp. 1619-1624.

[5] S. Xue, J. Feng, S. Guo, J. Peng, W.Q. Chu, and Z.Q. Zhu, "A New Iron Loss Model for Temperature Dependencies of Hysteresis and Eddy Current Losses in Electrical Machines," IEEE Trans. Magn., vol. 54, no. 1, Jan. 2018, Art ID 8100310.

[6] M. Ployard, A. Ammar, F. Gillon, and A. Benabou, "Iron loss computation of a hybrid excitation synchronous generator," International Symposium on Electromagnetic Fields in Mechatronics, Electrical and Electronic Engineering (ISEF), Nancy, 2015.

[7] C.P. Steinmetz, "On the law of hysteresis," in Proceedings of the IEEE, vol. 72, no. 2, pp. 197-221, Feb. 1984.

[8] R. Benlamine, Y. Benmessaoud, F. Dubas, and C. Espanet, "Nonlinear Adaptive Magnetic Equivalent Circuit of a Radial-Flux Interior Permanent-Magnet Machine Using Air-Gap Sliding-Line Technic," IEEE Vehicle Power and Propulsion Conference (VPPC), Belfort, 2017, pp. 1-6.

[9] P. Jandaud, L. Lambourg, and S. Harmand, "Aero-Thermal Optimization of a Heat Sink using Variable Neighbourhood Search," Journal of Applied Fluid Mechanics, vol. 9, special issue 1, pp. 3137, 2016.

[10] O. Messal, F. Dubas, R. Benlamine, A. Kedous-lebouc, C. Chillet, and C. Espanet, "Iron Losses in Electromagnetic Devices: Nonlinear Adaptive MEC \& Dynamic Hysteresis Model, " Preprints (MDPI: Energies), Jan. 2017, DOI: 2017010131.

[11] O. Messal, A-T Vo, M. Fassenet, P. Mas, S. Buffat, A. KedousLebouc, "Advanced approach for static part of loss-surface iron loss model", Journal of Magnetism and Magnetic Materials, vol. 502, May. 2020, 166401. 